\title{
The 9aaTAD activation domains in the four Yamanaka Oct4, Sox2, Myc, and Klf4 transcription factors essential during the stem cell development
}

\author{
Martin Piskacek $^{1 *}$, Kristina Jendruchova ${ }^{1}$, Martina Rezacova ${ }^{1}$, Marek Havelka ${ }^{1}$ \\ Norbert Gasparik ${ }^{1}$, Alena Hofrova ${ }^{1}$ and Andrea Knight ${ }^{*}$ \\ Running title: Nine-amino-acid TransActivation Domains

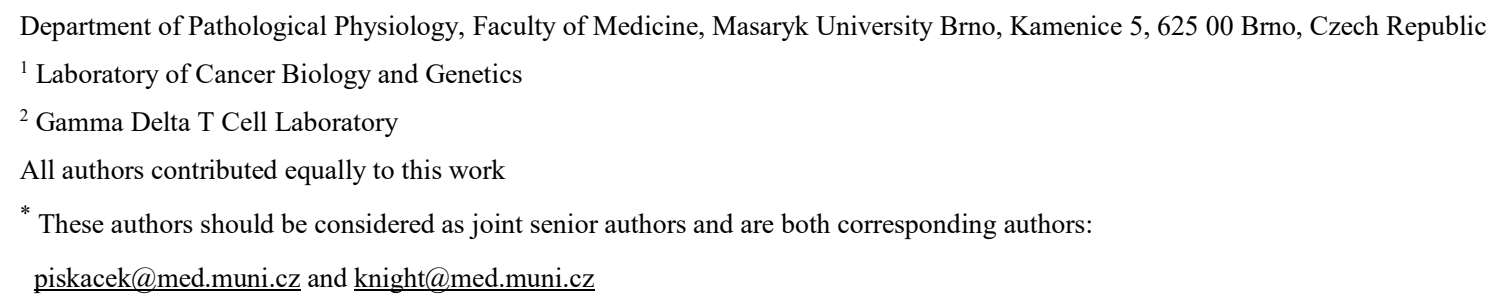

* These authors should be considered as joint senior authors and are both corresponding authors: piskacek@med.muni.cz and knight@med.muni.cz

Keywords: activation domain, 9aTAD, phase separation, condensate, Oct4, Pou5f, Sox2, Myc and Klf4.

\begin{abstract}
Somatic cells can be reprogrammed by the Yamanaka factors Oct4, Sox2, Myc and Klf4 activators into induced pluripotent stem cells. Throughout their genome, the Oct4, Sox 2 and Klf4 cooperate with mediators of transcription, where the DNA binding sites serve as scaffolds for the phase-separated transcriptional condensates at distinct genome loci. In this study, we identified the 9aaTAD activation domains as the common interaction interface of the Yamanaka factors for transcription machinery. All four activation domains were identified by our online 9aaTAD prediction service and experimentally confirmed as strong activators of transcription. We considered the mediator interactions granted by 9aaTADs as part of the Yamanaka factors ability to reprogram cell fate.
\end{abstract}




\section{Introduction}

Our longstanding effort has been to determine the Nine-amino-acid TransActivation Domains (9aaTADs) in eukaryotic activators. Previously, we identified the 9aaTAD in a large set of transcription activators that universally recruit multiple mediators of transcription (1-11). The 9aaTAD family is represented by Ga14, p53, MLL, TCF3/E2A and SREBP1. The 9aaTADs were found in the SP/KLF family (Sp1, Sp2, Sp3, Sp4, Klf1, Klf2, K1f3, Klf4, Klf5, Klf6, Klf7, Klf8, Klf12, Klf15, WT1), the SOX family (Sox18 and SoxE), in hormone receptors (RARa, HNF4, PPAR, VDR, NHR49), in yeast transcription factors (Oaf1, Pip2, Pdr1, Pdr3, Rtg3, Gln3, Gcn4, Pho4, Msn2, Msn4, Met4), and in artificial activators of transcription (P201, B42, p53-ECapLL, KBP 2.20, pRJR200, G80BP-A, G80BP-B (12-19).

Although the activation domains have enormous variability, they are universally recognized by transcriptional machinery throughout eukaryotes (20). The 9aaTADs have the competence to activate transcription as small peptides ( 9 to 14 amino acids long). Currently, all tested human 9aaTADs have been shown to be functional in yeast. Therefore, we considered the 9aaTADs universal function in all eukaryotes as a further ground property of the 9aaTAD family $(15,17,18,20,21)$. Besides the amino acid pattern, a specific distribution of amino acids in the 9aaTAD is essential. Among the characteristic features is a tandem of hydrophobic clusters surrounded by hydrophilic regions $(15,18)$. These hydrophobic clusters are often accompanied or are fully substituted by hydrophilic amino acids with aromatic side chains as are tryptophan (W) or tyrosine (Y), e.g. in p53. Accumulation of valines or isoleucines can compromise or fully inactivate the 9aaTAD function (22).

The 9aaTADs are well balanced with hydrophilic amino acids, which may be either positively or negatively charged. Some of them are acidic and negatively charged e.g. Gal4 others are positively charged e.g. Sp1. The general acidic character of activation domains is old and sadly fixed error, which still persists for Gal4 and also other activators (23). The Gal4 activation domain (DDVY N YLFD) is conserved only in the 9aaTAD region especially in ancestral orthologs as are Hansenula fabianii or Wickerhamomyces ciferrii, whose activation domain is hardly acidic (NDFY S LIFN)(24). Moreover, we recently demonstrated that the exchange of all negatively charged residues for positively charged ones and vice versa in Gal4 and respectively in Sp1 activation domains did not interfere with their function as strong activators of transcription (22).

The 9aaTADs bind to one or more of the mediator's domains on MED15 or CBP/p300 $(1,23)$. From structural data for the E2A and MLL activation domains in complex with the KIX 
domain of CBP mediator, the 9aaTADs form short helices whose lengths vary from 9 to 12 aa (14). Online 9aaTAD prediction (using a residue position matrix search and amino acid clustering) is available on www.piskacek.org. The curated 9aaTADs have been annotated on the protein database UniProt, which now accounts for 145 annotations with 39 human activators (https://www.uniprot.org/uniprot/?query=9aatad\&sort=score) (Including the current study, the list of 9aaTAD annotations will be further extended on 165 annotations with 52 human activators).

The Yamanaka transcription factors including the Oct4, Sox2, Myc and Klf4 activators, are all essential for chromatin remodelling and gene activation during the cell reprogramming (25). These activators can reprogram somatic cells into induced pluripotent stem cells (iPSCs) (26). In pluripotent cells, Oct4 / Pou5f from POU family associates with Sox 2 to maintain pluripotency or with Sox17 to induce primitive endoderm commitment. The direct interaction between Oct 4 and Sox 2 is DNA dependent and involves the POU helix A1 from Oct4 and the HMG helix A3 from Sox2 (27). Klf4 cooperates with Oct4 and Sox2 $(28,29)$ to establish embryonic stem cells (ESCs). Oct4 and Sox2 can form a complex and cooperate during cell reprogramming $(30,31)$. The activation domain and associated SUMO-interacting motif (SIM, amino acid pattern $\mathrm{K} / \mathrm{RxE}$ ) are required for KLF4 protein stability and are essential for cell pluripotency (32-34).

The SOX family are close relatives of transcription factor SRY (SOX for $\underline{\text { SRY }}$-related HMG box and SRY for sex-determining region $\underline{Y}$ ) (35-37). The SOX transcription factors are divided into groups $\mathrm{A}$ to $\mathrm{H}$ and are involved in cell fate determination, development and cancer $(38-41)$.

The most prominent member of the SOX family is Sox2, which supports cellular reprogramming and stem cell pluripotency (40). The Sox 2 transactivation is associated with the general TFIID activator complex (42) and with stem cell XPC activator complex $(38,43,44)$, with Oct4 (45), with Pax6 (46), with Trim24 (47) and with PARP-1 (48). Sox2 posttranslational modifications have been reported to modulate transactivation activity (49-51). Sox2-mediated cell reprogramming could be further enhanced by Sox 2 fusion with a strong viral activator VP16 (52). Sox1, Sox3, and Sox 15 can replace the function of Sox 2 in mouse ES $(53,54)$.

The gene expression programs, which are controlled by master transcription factors, define the identity of each cell. Recent studies have revealed that master activators form phaseseparated condensates with the mediators of transcription at specific genomic loci containing their binding sites (55). The phase separation is a universal cooperative mechanism for 
transcription, focusing the transcriptional machinery onto DNA enhancer sites, including Oct4, Sox 2 and Klf4 binding sites $(56,57)$. Moreover, activation domains drive nucleosome eviction after activators binding to specific genomic loci (58) and after Oct4 binding, the chromatin accessibility is facilitated by chromatin remodelling factors $(59,60)$.

In our study, we have focused on the of transcription factors Oct4, Sox2, Myc and Klf4 to determinate their activation interface for the interaction with mediators of transcription, which is a part of cell reprogramming.

\section{Results}

\section{POU family including Oct4}

We have performed our online 9aaTAD prediction for Pou5f/ Oct4 (9aaTAD prediction service online, www.piskacek.org) (18) and revealed a single perfect hit to amino acid sequence GHLASDFAF (Figure 1). By sequence alignment, we have identified the activation domains in other members of the POU family (Figure 1).

We generated LexA constructs, which included the prokaryotic DNA binding domain LexA and POU's region coding for the 9aaTAD from selected members of clade 1, 3, and 5 . The constructs were tested for their ability to activate transcription (Figure 2). Both tested human POU activation domains of Pit1 and Pou5f1 have the capacity to activate transcription. Less activity was observed for Pou5 orthologs in Callorhinus ursinus (cur Pou5, Northern fur seal, gene ID: XP_025704146) and Sarcophilus harrisii (shr Pou5, Tasmanian devil, gene ID: G3VJ82), but none in Lingula unguis (lak Pou, brachiopod, gene ID: XP_013392366) or Callorhinchus milii (cmk Pou5, Ghost shark, gene ID: XP_007894073).

\section{SOX family}

We have performed online 9aaTAD prediction for Sox 2 and revealed two hits above $80 \%$ match (Figure 1). The first hit was positioned within the DNA binding domain and was therefore excluded. The second hit was located in the Sox 2 region 272-280, which corresponds to reported 9aaTAD activation domains in Sox 18 (61) and SoxE (12). By sequence alignment, we have identified activation domains in other human members of the SOX family and their distal orthologs from early metazoans, such as Mnemiopsis leidyi (Ctenophora), Amphimedon queenslandica (Porifera), Strongylocentrotus purpuratus (Echinodermata) and Saccoglossus kowalevskii (Hemichordata), which shared significant similarity with Sox 2 and other members 
of the family (Figure 3). Importantly, members of the groups B and $\mathrm{F}$ have supported the common origin of their activation domains. In contrast, the well-studied paralogs SRY, Sox15 and Sox30 (62-66) have largely diverged and do not share a clear 9aaTAD motif or significant activation domain homology with the aforementioned members of SOX family.

We generated LexA constructs, which included the prokaryotic DNA binding domain LexA and SOX's region coding for the 9aaTAD from selected members of clade B, C, E and F. The constructs were tested for their ability to activate transcription (Figure 2). All tested SOX activation domains have the capacity to activate transcription.

\section{MYC family}

We have analysed the 9aaTAD activation domains in MYC activators. The MYC family has multiple conserved regions including MYC boxes MB0 to MBIV and the DNA binding domain (67) (Figure 4). From previous studies, the c-Myc region 105-143 was essential for transforming activity $(68,69)$. Insertion at codon 105 or removal of region 106-143 diminished c-Myc transcriptional activity (70). Based on this, we predicted the activation domain to be localised between MYC boxes MBI and MBII (Figure 4).

To identify the 9aaTAD activation domain, we ran our online 9aaTAD prediction service for trans-activating region 55-120 (localised between MYC boxes MBI and MBII) and revealed a 92\% hit (sequence EMVT E LLGG, region 100-120) (Figure 1). Similarly, we revealed a $100 \%$ hit for the c-Myc mutant, which has an intact activation potential despite of the internal deletion (fusion result for modified trans-activation region with modified sequence EMVT E LLVS, fusion of regions 100-105 to 144-146).

We have analysed several previously reported mutants with surprising phenotypes. Reported insertion of glutamic acid into c-Myc (EMVT EL/ E/LVS, region 100-105 / inserted E / 144-146) (70) diminished the 9aaTAD pattern and its function. The activation domain 9aaTAD was also destroyed in mutants with deletion 3-103 and 106-143. Nevertheless, partial activity was observed in mutants with deleted regions 41-103, 56-103, 93-103 (including also small inserts due to DNA manipulation), which seem to have a partial repair of their 9aaTAD motif (QSEL / E LLGG, ELLD / E LLGG and GSSI / E LLGG).

The longest reported construct with full activity included the c-Myc region 1-262 (69). Despite of the presence of the activation region, a longer construct including region 1-336 has lost abruptly the capacity to activate transcription. Similarly, the mutant with deleted region 791 lost the capacity to activate transcription (70). Additionally, mutants with deleted regions 353 or 145-304 have no capacity to activate transcription regardless of their activation domains 
(regions 55-100). Together, we concluded that in these mutants with intact activation domains, the local structural aberrations hindered function of their activation domains.

The 9aaTAD activation domains are well conserved in the active human Myc paralog N-Myc, but completely absent in human paralog L-Myc, what well corresponds with its poor activation potential (71). Interestingly, we found conservation of the activation domains in all three Myc paralogs in lobe-finned bony fish coelacanth (Latimeria chalumnae, fin-to-limb transition, related to lungfishes and tetrapods) but not in reptiles and other higher metazoans, which suggests that loss of L-Myc activation capacity have occurred already in early tetrapod evolution (Suppl. Figure S1). Besides the L-Myc clade, we found conservation of the activation domains in the entire Myc family from human to the last unicellular ancestor of animals, the Monosiga brevicollis (72).

The regions coding for predicted activation domains were fused with the DNA binding domain of LexA in construct i) mbr Myc for flagellate filozoans Monosiga brevicollis (gene ID: A9V5B4), ii) construct aqu Myc for poriferans Amphimedon queenslandica (gene ID: XP003390966), iii) constructs lch c-Myc, lch N-Myc, lch L-Myc for lobe-finned fish Latimeria chalumnae (gene IDs: XP005992710, XP005993959, XP006009573), and iv) constructs hsa cMyc and hsa N-Myc for humans. No construct was created for the human L-Myc, which has deleted activation domain and was reported as a poor activator (71). All tested Myc activation domains from human and coelacanth have the capacity to activate transcription (Figure 2). Previously, the accumulations of valines and isoleucines in activation domains of SP and KLF transcription factors were linked with their full or partial inhibition, which corresponds well to lower activities of mbr and aqu Myc constructs in our transactivation assay (22). 


\section{Discussion}

The activation domains have been reported as intrinsically disordered regions, which facilitate fuzzy binding with mediators of transcription. Their binding mechanism should be sequence independent because mutation of nearly every residue within is tolerated (23). In spite of enormous activation domain variability observed within the natural and also artificial activation domains, we generated a 9aaTAD pattern and prediction algorithm based on the amino acid distribution and clustering (18). In this and our other studies, the 9aaTAD online prediction (https://www.med.muni.cz/9aaTAD/index.php) generated reliable predictions, which led to the identification of over hundred activation domains, which have been experimentally confirmed as powerful activators of transcription. Moreover, the 9aaTAD structures seem to be helical after binding to mediators and their interaction with mediators were found not fussy but rather well fixed after binding e.g. MLL, E2A, Myb, p53 (1, 14, 73, 74). We also observed high similarity and partial identity in some of the 9aaTADs e.g. MLL

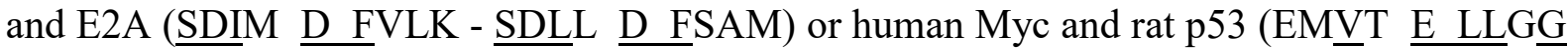
- QDEA E LLEG ) or human / Crassostrea gigas KLF4 and Oaf2 (LLDL D FIL / LLDY D $\underline{\text { FIL - LFDY D FLF }})(14,22)$. All that supports that 9aaTAD domains have a natural prevalence for some variants despite their tentatively huge variability.

In our study, we have identified activation domains in all four Yamanaka factors, Oct4, Sox2, Myc, and Klf4. All of them fulfil the criteria for the 9aaTAD domains, which activated transcription as short peptides. The loss of 9aaTAD in human L-Myc (as well as in reptiles and higher animals) explained its poor activator function and pointed to the functional diversification of MYC family during vertebrates' evolution. The members of SOX clades B, F, C, E possess functional 9aaTADs, could partially substitute for each other and their function also largely diversified first in vertebrates. Similarly, the KLF family and their successor SP family (Klf1, Klf2, Klf3, Klf4, Klf5, Klf6, Klf7, Klf8, Klf12, Klf15, WT1, respectively Sp1, $\mathrm{Sp} 2, \mathrm{Sp} 3$, and Sp4), all possess a functional 9aaTAD and have versatile functions in cell fate determination.

We found the 9aaTAD pattern deterioration in Callorhinchus milii (Ghost shark) cmk Pit1 (Pou1 clade) indicating that the Pit1 9aaTAD activation domain is the latter evolution event in vertebrates. Similarly, Pou5 orthologs in Callorhinus ursinus (cur Pou5, Northern fur seal) and Sarcophilus harrisii (Tasmanian devil) have less transcriptional activity and even the loss 
of activity was found in Lingula unguis (brachiopod), which has also a deteriorated 9aaTAD motif. Moreover, we found a similar trend in Myc orthologs from flagellate filozoans Monosiga brevicollis and poriferans Amphimedon queenslandica, where the activation domains have substantially compromised function (disadvantageous accumulation of valines and isoleucines in their 9aaTADs, e.g. inactivated 9aaTAD in Sp2).

By cooperative interactions, active enhancers interact with mediators of transcription to enable assembly of the transcriptional machinery. The phase separation contributes to stabilization of transcription machinery at the specific genomic loci even at very low protein concentrations. Throughout the genome, the Oct4, Sox 2 and Klf4 binding sites and mediators of transcription distribution have an exponential occurrence correlation, whereby the DNA binding sites serve as scaffolds for the phase-separated transcriptional condensate and cooperate during cell reprogramming. In summary, we consider the mediator interaction interface facilitated by the 9aaTADs in higher vertebrates as a part of Yamanaka factors ability to reprogram cell fate.

\section{Methods}

Constructs. The construct pBTM116-HA was generated by insertion of an HA cassette into the EcoRI site of the vector pBTM116. All constructs were generated by PCR and subcloned into the pBTM116 EcoRI and BamHI sites. All constructs had a spacer of three amino acids inserted into the EcoRI site: the peptide GSG. All constructs were sequenced by Eurofins Genomics. Further detailed information about constructs and primer sequences is available on request.

Assessment of enzyme activities. $\beta$-galactosidase activity was determined in the yeast strain L40 [58, 59]. The strain L40 has a chromosomally integrated lacZ reporter driven by the lexA operator. In all hybrid assays, we used the $2 \mu$ vector pBTM1 16 for generation of LexA hybrids. The yeast strain L40, Saccharomyces cerevisiae genotype: MATa ade2 his3 leu2 trp1 LYS::lexA-HIS3 URA3::lexA-LacZ, is deposited at the ATCC (\#MYA-3332). The average value of the $\beta$-galactosidase activities from three independent transformants is presented as a percentage of the reference with the standard deviations (means plus and minus SDs; $n=3$ ). We standardized all results to the previously reported Gal4 construct $\mathrm{HaY}$ including the 9aaTAD with the activity set to $100 \%$ [14]. 
Databases used in the study. UniProt, ExPASy, NCBI, Ensembl Metazoa, KEGG http://www.genome.jp, Japanese Lamprey Genome Project http://jlampreygenome.imcb.astar.edu.sg/blast/, Sun Yat-Sen University Lancelet Genome Project http://genome.bucm.edu.cn/lancelet/blast.php, Compagen Genomics Platform http://www.compagen.org/blast.html, Florida University Neurobase https://neurobase.rc.ufl.edu/, UCSC genomic annotation https://genome.ucsc.edu, NIH https://research.nhgri.nih.gov/mnemiopsis/blast/.

\section{Acknowledgements}

This work was supported by the Ministry of Health of the Czech Republic AZV NV19-0500410 .

\section{Author contributions}

MP, KJ, MR, and MH performed the experiments. MP conceived the project. MP and AK wrote the manuscript. All authors have contributed critical intellectual content and have approved the final manuscript.

\section{Conflict of interest}

The authors declare no potential conflicts of interest. 


\section{Figure Legends}

Figure 1. Activation domain prediction. The online 9aaTAD prediction service for activation domain was applied on Pou5F / Oct4, Sox2, Myc (prediction for trans-activation region 50-120 localized experimentally) and Klf4. Algorithm for the 9aaTAD amino acid pattern was applied in the search, and region clustering conformity was assessed by percentage.

Figure 2. Transactivation Assay. The regions with the identified 9aaTAD activation domains were tested in a reporter assay with hybrid LexA DNA binding domain for the capacity to activate transcription. The average value of the $\beta$-galactosidase activities from two independent transformants is presented as a percentage of the reference with standard deviation (means and plusmn; $\mathrm{SD} ; \mathrm{n}=3$ ). We standardized the results to positive control $\mathrm{p} 53$ construct $6 \mathrm{p} 53$, which was set to $100 \%$. The 9aaTADs activation domains are colored for faster orientation. Deuterated 9aaTADs or their mismatch are in grey. Abbreviations: Homo sapiens (hsa), Callorhinchus milii (cmk, Ghost shark, gene ID: XP_007894073), Callorhinus ursinus (cur Pou5, Northern fur seal, gene ID: XP_025704146), Sarcophilus harrisii (shr Pou5, Tasmanian devil, gene ID: G3VJ82), Lingula unguis (lak Pou, brachiopod, gene ID: XP_013392366), Mnemiopsis leidyi (mle SoxB, comb jelly, gene ID: A0A059XHC3), Amphimedon queenslandica (aqu SoxB, gene ID: B1A9Y6), Strongylocentrotus purpuratus (spu SoxB, purple sea urchin, gene ID: Q9Y0D7 and spu SoxF, gene ID: W4YEI9), Saccoglossus kowalevskii (sko SoxB, hemichordate, common ancestor of chordata, gene ID: Q7YTD4 and sko SoxF, gene ID: B5THP2), Monosiga brevicollis (mbe Myc, filozoans, last unicellular ancestor of animals, gene ID: A9V5B4), Amphimedon queenslandica (aqu Myc, poriferans, gene ID: XP003390966), Latimeria chalumnae (1ch c-Myc, lch N-Myc, and lch L-Myc, lobe-finned fish, related to lungfishes and tetrapods, gene IDs: XP005992710, XP005993959, XP006009573).

Figure 3. Alignment of SOX family. The C-terminal regions of SOX proteins were aligned by sequence similarities to Sox 2 and predicted 9aaTAD activation domain (9aaTAD prediction service online, www.Piskacek.org). The Sox orthologs from early diverged eukaryotes Mnemiopsis leidyi (mle SoxB, gene ID: A0A059XHC3), Amphimedon queenslandica (aqu SoxB, gene ID: B1A9Y6), Strongylocentrotus purpuratus (spu SoxB, gene ID: Q9Y0D7 and spu SoxF, gene ID: W4YEI9) and Saccoglossus kowalevskii (sko SoxB, gene ID: Q7YTD4 and sko SoxF, gene ID: B5THP2) have strong conservation of 9aaTAD. Diversification of the 
9aaTAD motif, especially in position p5 (in red) could be seen in human SoxF but not in spu SoxF and sko SoxF. The members of SoxE clade contain two activation domains; the 9aaTADsI have more conserved sequence but the 9aaTADs-II have more conserved position in the protein and are associated with the SOX C-terminal domains, similarly to the 9aaTADs in all other SOX clades. The 9aaTADs activation domains are colored for faster orientation. Dots in sequences represent stop codon.

Figure 4. Alignment of the MYC family. The N-terminal regions of MYC proteins were aligned by sequence similarities and their predicted 9aaTAD activation domains are shown. The 9aaTADs activation domains are colored for faster orientation. A) Contrary to coelacanth (Latimeria chalumnae, fin-to-limb transition, related to lungfishes and tetrapods), the L-Myc from humans, reptiles and higher animals have no 9aaTAD motif and the corresponding region is deleted. B) The MYC clades with conservation MYB box O, I and II are shown. The deletion of activation domain in L clade are in grey box. Conservation of threonine in position 55 is highlighted in red. Pseudo repeat of the 9aaTAD motif with similarity to Sp2 9aaTAD is shown. 


\section{References}

1. Teufel,D.P., Freund,S.M., Bycroft,M. and Fersht,A.R. (2007) Four domains of p300 each bind tightly to a sequence spanning both transactivation subdomains of p53. Proc. Natl. Acad. Sci. U.S.A., 104, 7009-7014.

2. Gamper,A.M. and Roeder,R.G. (2008) Multivalent Binding of p53 to the STAGA Complex Mediates Coactivator Recruitment after UV Damage. Mol Cell Biol, 28, 2517-2527.

3. Feng,H., Jenkins,L.M.M., Durell,S.R., Hayashi,R., Mazur,S.J., Cherry,S., Tropea,J.E., Miller,M., Wlodawer,A., Appella,E., et al. (2009) Structural basis for p300 Taz2-p53 TAD1 binding and modulation by phosphorylation. Structure, 17, 202-210.

4. Ferreon,J.C., Lee,C.W., Arai,M., Martinez-Yamout,M.A., Dyson,H.J. and Wright,P.E. (2009) Cooperative regulation of $\mathrm{p} 53$ by modulation of ternary complex formation with $\mathrm{CBP} / \mathrm{p} 300$ and HDM2. Proc. Natl. Acad. Sci. U.S.A., 106, 6591-6596.

5. Jenkins,L.M.M., Yamaguchi,H., Hayashi,R., Cherry,S., Tropea,J.E., Miller,M., Wlodawer,A., Appella,E. and Mazur,S.J. (2009) Two distinct motifs within the p53 transactivation domain bind to the Taz2 domain of $\mathrm{p} 300$ and are differentially affected by phosphorylation. Biochemistry, 48, 1244-1255.

6. Thakur,J.K., Arthanari,H., Yang,F., Chau,K.H., Wagner,G. and Näär,A.M. (2009) Mediator subunit Gal11p/MED15 is required for fatty acid-dependent gene activation by yeast transcription factor Oaf1p. J. Biol. Chem., 284, 4422-4428.

7. Choi,Y., Asada,S. and Uesugi,M. (2000) Divergent hTAFII31-binding motifs hidden in activation domains. J. Biol. Chem., 275, 15912-15916.

8. Uesugi,M. and Verdine,G.L. (1999) The alpha-helical FXXPhiPhi motif in p53: TAF interaction and discrimination by MDM2. Proc. Natl. Acad. Sci. U.S.A., 96, 14801-14806.

9. Piskacek,M. (2009) 9aaTADs mimic DNA to interact with a pseudo-DNA Binding Domain KIX of Med15 (Molecular Chameleons). Nature Precedings, 10.1038/npre.2009.3939.1.

10. Piskacek,M. (2009) Common Transactivation Motif 9aaTAD recruits multiple general co-activators TAF9, MED15, CBP and p300. Nature Precedings, 10.1038/npre.2009.3488.2.

11. Di Lello,P., Jenkins,L.M.M., Jones,T.N., Nguyen,B.D., Hara,T., Yamaguchi,H., Dikeakos,J.D., Appella,E., Legault,P. and Omichinski,J.G. (2006) Structure of the Tfb1/p53 complex: Insights into the interaction between the p62/Tfb1 subunit of TFIIH and the activation domain of p53. Mol. Cell, 22, 731-740.

12. Haseeb,A. and Lefebvre,V. The SOXE transcription factors-SOX8, SOX9 and SOX10-share a bipartite transactivation mechanism. Nucleic Acids Res, 10.1093/nar/gkz523.

13. Piskacek,M. (2009) 9aaTAD Prediction result (2006). Nature Precedings, 10.1038/npre.2009.3984.1.

14. Piskacek,M., Vasku,A., Hajek,R. and Knight,A. (2015) Shared structural features of the 9aaTAD family in complex with CBP. Mol Biosyst, 11, 844-851. 
15. Piskacek,M., Havelka,M., Rezacova,M. and Knight,A. (2016) The 9aaTAD Transactivation Domains: From Gal4 to p53. PLOS ONE, 11, e0162842.

16. Piskacek,M., Havelka,M., Rezacova,M. and Knight,A. (2017) The 9aaTAD Is Exclusive Activation Domain in Gal4. PLOS ONE, 12, e0169261.

17. Piskacek,M., Havelka,M., Jendruchova,K. and Knight,A. (2018) Nuclear hormone receptors: Ancient 9aaTAD and evolutionally gained NCoA activation pathways. The Journal of Steroid Biochemistry and Molecular Biology, 10.1016/j.jsbmb.2018.11.008.

18. Piskacek,S., Gregor,M., Nemethova,M., Grabner,M., Kovarik,P. and Piskacek,M. (2007) Nineamino-acid transactivation domain: establishment and prediction utilities. Genomics, 89, 756-768.

19. Sandholzer,J., Hoeth,M., Piskacek,M., Mayer,H. and de Martin,R. (2007) A novel 9-amino-acid transactivation domain in the C-terminal part of Sox18. Biochem. Biophys. Res. Commun., 360, 370-374.

20. Kakidani,H. and Ptashne,M. (1988) GAL4 activates gene expression in mammalian cells. Cell, 52, 161-167.

21. Fields,S. and Jang,S.K. (1990) Presence of a potent transcription activating sequence in the p53 protein. Science, 249, 1046-1049.

22. Piskacek,M., Havelka,M., Jendruchova,K., Knight,A. and Keegan,L.P. (2019) The evolution of the 9aaTAD domain in Sp2 proteins: inactivation with valines and intron reservoirs. Cell. Mol. Life Sci., 10.1007/s00018-019-03251-w.

23. Tuttle,L.M., Pacheco,D., Warfield,L., Hahn,S. and Klevit,R.E. (2019) Mediator subunit Med15 dictates the conserved 'fuzzy' binding mechanism of yeast transcription activators Gal4 and Gcn4 Molecular Biology.

24. Piskacek,M., Havelka,M., Rezacova,M. and Knight,A. (2017) Gal4 activation domain 9aaTAD could be inactivated by adjacent mini-inhibitory domain and reactivated by distal re-activation domain. bioRxiv, 10.1101/110882.

25. Chen,K., Long,Q., Xing,G., Wang,T., Wu,Y., Li,L., Qi,J., Zhou,Y., Ma,B., Schöler,H.R., et al. (2019) Heterochromatin loosening by the Oct4 linker region facilitates KIf4 binding and iPSC reprogramming. The EMBO Journal, 0, e99165.

26. Takahashi,K. and Yamanaka,S. (2006) Induction of Pluripotent Stem Cells from Mouse Embryonic and Adult Fibroblast Cultures by Defined Factors. Cell, 126, 663-676.

27. Lam,C.S., Mistri,T.K., Foo,Y.H., Sudhaharan,T., Gan,H.T., Rodda,D., Lim,L.H., Chou,C., Robson,P., Wohland,T., et al. (2012) DNA-dependent Oct4-Sox2 interaction and diffusion properties characteristic of the pluripotent cell state revealed by fluorescence spectroscopy. Biochem. J., 448, 21-33.

28. Nakatake,Y., Fukui,N., Iwamatsu,Y., Masui,S., Takahashi,K., Yagi,R., Yagi,K., Miyazaki,J., Matoba,R., Ko,M.S.H., et al. (2006) KIf4 Cooperates with Oct3/4 and Sox2 To Activate the Lefty1 Core Promoter in Embryonic Stem Cells. Mol Cell Biol, 26, 7772-7782. 
29. Wei,Z., Yang,Y., Zhang,P., Andrianakos,R., Hasegawa,K., Lyu,J., Chen,X., Bai,G., Liu,C., Pera,M., et al. (2009) KIf4 interacts directly with Oct4 and Sox2 to promote reprogramming. Stem Cells, 27, 2969-2978.

30. Lodato,M.A., Ng,C.W., Wamstad,J.A., Cheng,A.W., Thai,K.K., Fraenkel,E., Jaenisch, R. and Boyer, L.A. (2013) SOX2 Co-Occupies Distal Enhancer Elements with Distinct POU Factors in ESCs and NPCs to Specify Cell State. PLOS Genetics, 9, e1003288.

31. Ng,C.K.L., Li,N.X., Chee,S., Prabhakar,S., Kolatkar,P.R. and Jauch,R. (2012) Deciphering the Sox-Oct partner code by quantitative cooperativity measurements. Nucleic Acids Res, 40, 4933-4941.

32. Dhaliwal,N.K., Abatti,L.E. and Mitchell,J.A. (2019) KLF4 protein stability regulated by interaction with pluripotency transcription factors overrides transcriptional control. Genes Dev., 33, 1069-1082.

33. Du,J.X., McConnell,B.B. and Yang,V.W. (2010) A Small Ubiquitin-related Modifier-interacting Motif Functions as the Transcriptional Activation Domain of Krüppel-like Factor 4. J. Biol. Chem., 285, 28298-28308.

34. Presnell,J.S., Schnitzler,C.E. and Browne,W.E. (2015) KLF/SP Transcription Factor Family Evolution: Expansion, Diversification, and Innovation in Eukaryotes. Genome Biol Evol, 7, 2289-2309.

35. Bowles,J., Schepers,G. and Koopman,P. (2000) Phylogeny of the SOX family of developmental transcription factors based on sequence and structural indicators. Dev. Biol., 227, 239-255.

36. Koopman,P., Schepers,G., Brenner,S. and Venkatesh,B. (2004) Origin and diversity of the SOX transcription factor gene family: genome-wide analysis in Fugu rubripes. Gene, 328, 177-186.

37. Wegner,M. (2011) SOX after SOX: SOXession regulates neurogenesis. Genes Dev., 25, 2423-2428.

38. Cattoglio,C., Zhang,E.T., Grubisic,I., Chiba,K., Fong,Y.W. and Tjian,R. (2015) Functional and mechanistic studies of XPC DNA-repair complex as transcriptional coactivator in embryonic stem cells. Proc. Natl. Acad. Sci. U.S.A., 112, E2317-2326.

39. Kormish,J.D., Sinner,D. and Zorn,A.M. (2010) Interactions between SOX factors and Wnt/betacatenin signaling in development and disease. Dev. Dyn., 239, 56-68.

40. Takahashi,K. and Yamanaka,S. (2016) A decade of transcription factor-mediated reprogramming to pluripotency. Nat. Rev. Mol. Cell Biol., 17, 183-193.

41. Tosic,N., Petrovic,I., Grujicic,N.K., Davidovic,S., Virijevic,M., Vukovic,N.S., Pavlovic,S. and Stevanovic,M. (2018) Prognostic significance of SOX2, SOX3, SOX11, SOX14 and SOX18 gene expression in adult de novo acute myeloid leukemia. Leuk. Res., 67, 32-38.

42. Pijnappel,W.W.M.P., Esch,D., Baltissen,M.P.A., Wu,G., Mischerikow,N., Bergsma,A.J., van der Wal,E., Han,D.W., Bruch,H. vom, Moritz,S., et al. (2013) A central role for TFIID in the pluripotent transcription circuitry. Nature, 495, 516-519.

43. Lafrance-Vanasse,J., Arseneault,G., Cappadocia,L., Legault,P. and Omichinski,J.G. (2013) Structural and functional evidence that Rad4 competes with Rad2 for binding to the Tfb1 subunit of TFIIH in NER. Nucleic Acids Res., 41, 2736-2745. 
44. Zhang,E.T., He,Y., Grob,P., Fong,Y.W., Nogales,E. and Tjian,R. (2015) Architecture of the human XPC DNA repair and stem cell coactivator complex. PNAS, 112, 14817-14822.

45. Chang,Y.K., Srivastava,Y., Hu,C., Joyce,A., Yang,X., Zuo,Z., Havranek,J.J., Stormo,G.D. and Jauch,R. (2017) Quantitative profiling of selective Sox/POU pairing on hundreds of sequences in parallel by Coop-seq. Nucleic Acids Res., 45, 832-845.

46. Kamachi,Y., Uchikawa,M., Tanouchi,A., Sekido,R. and Kondoh,H. (2001) Pax6 and SOX2 form a coDNA-binding partner complex that regulates initiation of lens development. Genes Dev., 15, $1272-1286$.

47. Rafiee,M.-R., Girardot,C., Sigismondo,G. and Krijgsveld,J. (2016) Expanding the Circuitry of Pluripotency by Selective Isolation of Chromatin-Associated Proteins. Mol. Cell, 64, 624-635.

48. Terrados,G., Finkernagel,F., Stielow,B., Sadic,D., Neubert,J., Herdt,O., Krause,M., Scharfe,M., Jarek,M. and Suske,G. (2012) Genome-wide localization and expression profiling establish $\mathrm{Sp} 2$ as a sequence-specific transcription factor regulating vitally important genes. Nucleic Acids Res., 40, 7844-7857.

49. Kamachi,Y. and Kondoh,H. (2013) Sox proteins: regulators of cell fate specification and differentiation. Development, 140, 4129-4144.

50. Tsuruzoe,S., Ishihara,K., Uchimura,Y., Watanabe,S., Sekita,Y., Aoto,T., Saitoh,H., Yuasa,Y., Niwa,H., Kawasuji,M., et al. (2006) Inhibition of DNA binding of Sox2 by the SUMO conjugation.

Biochem. Biophys. Res. Commun., 351, 920-926.

51. Van Hoof,D., Muñoz,J., Braam,S.R., Pinkse,M.W.H., Linding,R., Heck,A.J.R., Mummery,C.L. and Krijgsveld,J. (2009) Phosphorylation dynamics during early differentiation of human embryonic stem cells. Cell Stem Cell, 5, 214-226.

52. Narayan,S., Bryant,G., Shah,S., Berrozpe,G. and Ptashne,M. (2017) OCT4 and SOX2 Work as Transcriptional Activators in Reprogramming Human Fibroblasts. Cell Rep, 20, 1585-1596.

53. Adikusuma,F., Pederick,D., McAninch,D., Hughes,J. and Thomas,P. (2017) Functional Equivalence of the SOX2 and SOX3 Transcription Factors in the Developing Mouse Brain and Testes. Genetics, 206, 1495-1503.

54. Niwa,H., Nakamura,A., Urata,M., Shirae-Kurabayashi,M., Kuraku,S., Russell,S. and Ohtsuka,S. (2016) The evolutionally-conserved function of group B1 Sox family members confers the unique role of Sox2 in mouse ES cells. BMC Evol. Biol., 16, 173.

55. Strom,A.R. and Brangwynne,C.P. (2019) The liquid nucleome - phase transitions in the nucleus at a glance. J Cell Sci, 132.

56. Shrinivas,K., Sabari,B.R., Coffey,E.L., Klein,I.A., Boija,A., Zamudio,A.V., Schuijers,J., Hannett,N.M., Sharp,P.A., Young,R.A., et al. (2019) Enhancer Features that Drive Formation of Transcriptional Condensates. Mol. Cell, 75, 549-561.e7.

57. Zamudio,A.V., Dall'Agnese,A., Henninger,J.E., Manteiga,J.C., Afeyan,L.K., Hannett,N.M., Coffey,E.L., Li,C.H., Oksuz,O., Sabari,B.R., et al. (2019) Mediator Condensates Localize Signaling Factors to Key Cell Identity Genes. Mol. Cell, 10.1016/j.molcel.2019.08.016. 
58. Gutiérrez,J.L., Chandy,M., Carrozza,M.J. and Workman,J.L. (2007) Activation domains drive nucleosome eviction by SWI/SNF. The EMBO Journal, 26, 730-740.

59. King,H.W. and Klose,R.J. (2017) The pioneer factor OCT4 requires the chromatin remodeller BRG1 to support gene regulatory element function in mouse embryonic stem cells. eLife, 6 , e22631.

60. Suzuki,H.I., Young,R.A. and Sharp,P.A. (2017) Super-Enhancer-Mediated RNA Processing Revealed by Integrative MicroRNA Network Analysis. Cell, 168, 1000-1014.e15.

61. Sandholzer,J., Hoeth,M., Piskacek,M., Mayer,H. and de Martin,R. (2007) A novel 9-amino-acid transactivation domain in the C-terminal part of Sox18. Biochem. Biophys. Res. Commun., 360, 370-374.

62. Berta,P., Hawkins,J.R., Sinclair,A.H., Taylor,A., Griffiths,B.L., Goodfellow,P.N. and Fellous,M. (1990) Genetic evidence equating SRY and the testis-determining factor. Nature, 348, 448450.

63. Feng,C.-W.A., Spiller,C., Merriner,D.J., O'Bryan,M.K., Bowles,J. and Koopman,P. (2017) SOX30 is required for male fertility in mice. Sci Rep, 7, 17619.

64. Ito,S., Yamane,M., Ohtsuka,S. and Niwa,H. (2014) The C-terminal region of Xpc is dispensable for the transcriptional activity of Oct3/4 in mouse embryonic stem cells. FEBS Lett., 588, 11281135.

65. McDowall,S., Argentaro,A., Ranganathan,S., Weller,P., Mertin,S., Mansour,S., Tolmie,J. and Harley,V. (1999) Functional and structural studies of wild type SOX9 and mutations causing campomelic dysplasia. J. Biol. Chem., 274, 24023-24030.

66. Roumaud,P., Haché,J. and Martin,L.J. (2018) Expression profiles of Sox transcription factors within the postnatal rodent testes. Mol Cell Biochem, 10.1007/s11010-018-3302-3.

67. Cowling,V.H. and Cole,M.D. (2006) Mechanism of transcriptional activation by the Myc oncoproteins. Semin. Cancer Biol., 16, 242-252.

68. Barrett,J.F., Lee,L.A. and Dang,C.V. (2005) Stimulation of Myc transactivation by the TATA binding protein in promoter-reporter assays. BMC Biochem., 6, 7 .

69. Kato,G.J., Barrett,J., Villa-Garcia,M. and Dang,C.V. (1990) An amino-terminal c-myc domain required for neoplastic transformation activates transcription. Mol. Cell. Biol., 10, 59145920.

70. Stone,J., de Lange,T., Ramsay,G., Jakobovits,E., Bishop,J.M., Varmus,H. and Lee,W. (1987) Definition of regions in human c-myc that are involved in transformation and nuclear localization. Mol Cell Biol, 7, 1697-1709.

71. Barrett,J., Birrer,M.J., Kato,G.J., Dosaka-Akita,H. and Dang,C.V. (1992) Activation domains of LMyc and c-Myc determine their transforming potencies in rat embryo cells. Mol. Cell. Biol., 12, 3130-3137.

72. King,N., Westbrook,M.J., Young,S.L., Kuo,A., Abedin,M., Chapman,J., Fairclough,S., Hellsten,U., Isogai,Y., Letunic,I., et al. (2008) The genome of the choanoflagellate Monosiga brevicollis and the origin of metazoans. Nature, 451, 783-788. 
bioRxiv preprint doi: https://doi.org/10.1101/2019.12.15.876706; this version posted December 15, 2019. The copyright holder for this preprint (which was not certified by peer review) is the author/funder, who has granted bioRxiv a license to display the preprint in perpetuity. It is made available under aCC-BY-NC-ND 4.0 International license.

73. Goto,N.K., Zor,T., Martinez-Yamout,M., Dyson,H.J. and Wright,P.E. (2002) Cooperativity in transcription factor binding to the coactivator CREB-binding protein (CBP). The mixed lineage leukemia protein (MLL) activation domain binds to an allosteric site on the KIX domain. $J$. Biol. Chem., 277, 43168-43174.

74. Krois,A.S., Ferreon,J.C., Martinez-Yamout,M.A., Dyson,H.J. and Wright,P.E. (2016) Recognition of the disordered $\mathrm{p} 53$ transactivation domain by the transcriptional adapter zinc finger domains of CREB-binding protein. Proc. Natl. Acad. Sci. U.S.A., 113, E1853-1862. 


\section{Online prediction for activation domains}

The 9aaTAD prediction result for the Pou5F / Oct4 activator

less stringent pattern resulted in a single perfect match online 9aaTAD prediction service www.med.muni.cz/9aaTAD

perfect match

The 9aaTAD prediction result for the Sox 2 activator

less stringent pattern, cut off $80 \%$ match

Sequence

MNAFMVWSR

DMISMYLPG
$\mathrm{RC} 3 \mathrm{RC} 4$

RC5 RC6 $\mathrm{RC} 7 \quad \mathrm{RC} 8 \quad \mathrm{RC} 9 \quad \mathrm{RC} 10 \quad \mathrm{RC} 11 \quad \mathrm{RC} 12$ = Rules for amino acid clustering

$\begin{array}{ccccccc}\mathrm{RC} 8 & \mathrm{RC} 9 & \mathrm{RC} 10 & \mathrm{RC} 11 & \mathrm{RC} 12 & = & \text { Rules for amino acid clustering } \\ + & + & + & + & + & 83 \% \text { match }\end{array}$

$83 \%$ match

The 9aaTAD prediction result for the c-Myc trans-activating region 1-120

less stringent pattern, cut off $80 \%$ match

Sequence

MPLNVSFTN

EMVTELLGG

Start
1

100108

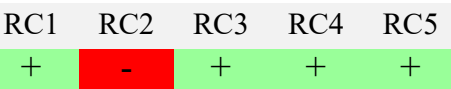

$+\quad+\quad+$
RC6 RC7 RC8 RC9 RC10 RC11 RC12 = Rules for amino acid clustering

$+\quad+\quad+\quad+\quad+\quad+\quad+-\quad+\quad 83 \%$ match

The 9aaTAD prediction result for the KLF4 activator most stringent pattern resulted in a single perfect match

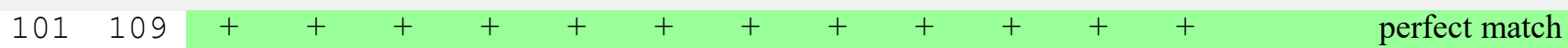


Transactivation assay

\section{Pou1 clade}

Pou predecessor

\section{SoxB clade}

SoxC clade

SoxE/F clade (TADI)

SoxE clade

(TADII)

hsa Pit1

cmk Pit1

hsa Pou5f1/Oct4

cur Pou 5

shr Pou 5

lak Pou

hsa Sox1-3

\section{hsa Sox 4}

hsa $\operatorname{Sox} 17$

hsa Sox9

hsa Sox8

$\begin{array}{ll}\text { c-Myc clade } & \text { hsa c-Myc } \\ & \text { lch C-Myc } \\ \text { N-Myc clade } & \text { hsa N-Myc } \\ & \text { lch N-Myc } \\ \text { L-Myc clade } & \text { lch L-MYc }\end{array}$

Myc predecessors aqu Myc

mbe Myc

p53 - 9aATAD

empty vector peptides used in assay

ID

Position

Reporter activation

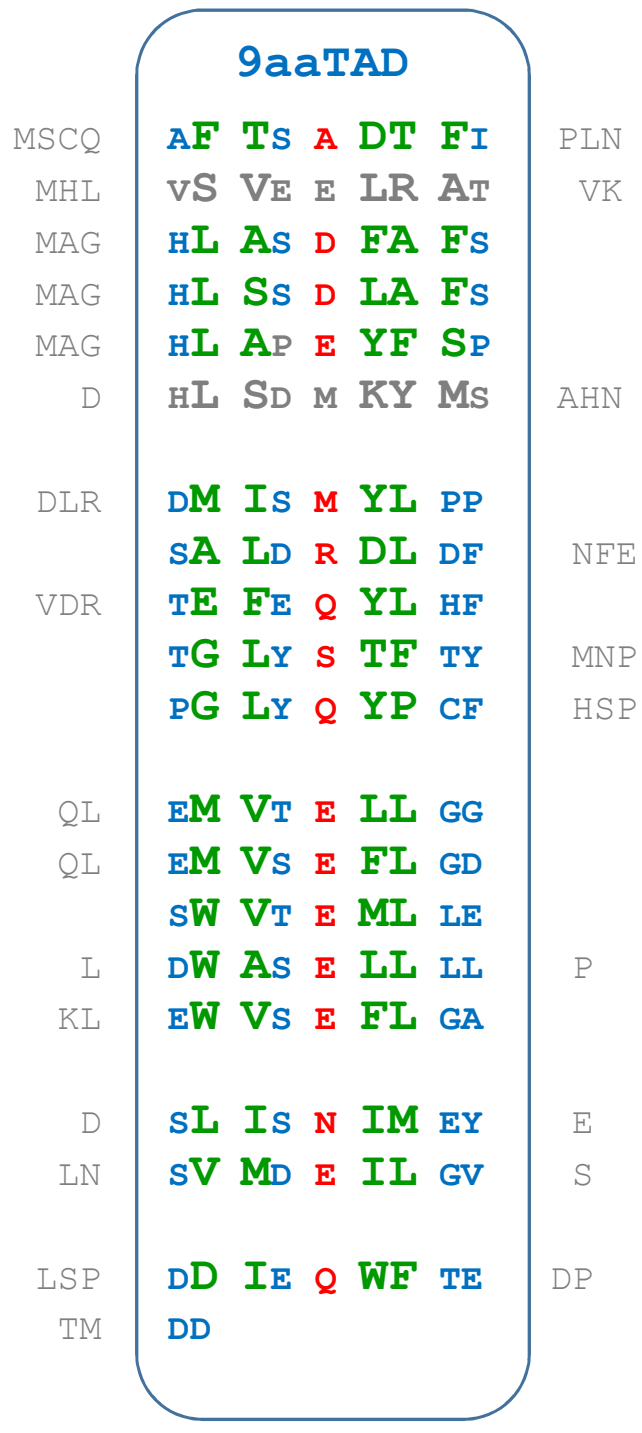

$\begin{array}{lr}\text { po1 } & 1-16 \\ \text { po2 } & 1-14 \\ \text { po6 } & 1-12 \\ \text { po8 } & 1-12 \\ \text { po7 } & 1-12 \\ \text { po11 } & 37-49 \\ & \\ \text { hS3 } & 396-407 \\ \text { hS4 } & 426-437 \\ \text { hS17 } & 358-371 \\ \text { hS9 } & 461-471 \\ \text { hS8 } & 401-411 \\ & \\ \text { hsa-C } & 98-108 \\ \text { Ich-C } & 79-89 \\ \text { hsa-N } & 76-84 \\ \text { Ich-N } & 94-104 \\ \text { Ich-L } & 59-69 \\ & \\ \text { aqu } & 99-109 \\ \text { mbr } & 74-85\end{array}$

$6 \mathrm{p} 53$

Hdd

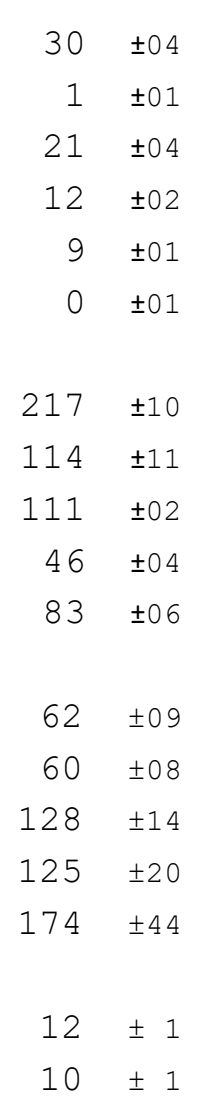

set to $100 \pm 11$

$0 \quad \pm 01$ 


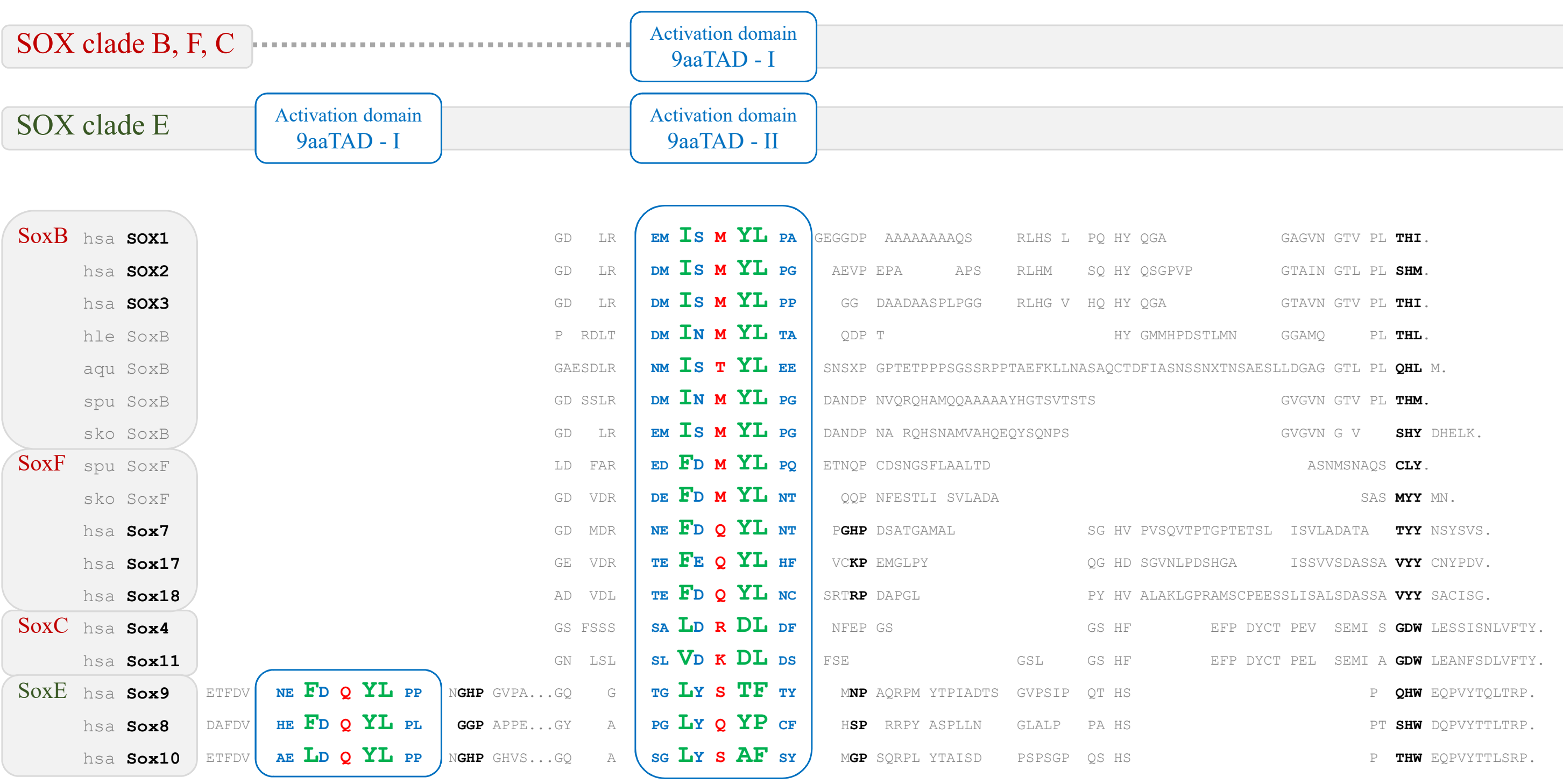




\begin{tabular}{|c|c|c|c|c|c|c|c|c|c|c|}
\hline \multicolumn{2}{|l|}{ MYC family } & \multicolumn{3}{|c|}{$\begin{array}{c}\text { Activation domain } \\
\text { 9aaTAD }\end{array}$} & & & & & & $\begin{array}{l}\text { MYC box II } \\
\quad \text { MBII }\end{array}$ \\
\hline L-Myc (with 9aaTAD deletion) & GIG PPE & $\mathrm{PW}$ & $\mathrm{P}$ & GG & & & & CT GDEAESR & GHSKGWGRNY & ASIIRRDCMWSG \\
\hline N-Myc & HSS EPP & sW & Vт E ML & LE & NELW & G & & $\mathrm{SP}$ AEEDAF & GLGGLGGLTP & NPVILQDCMWSG \\
\hline C-Myc & STA TQL & EM & Vт E LL & GG & DMVN & QSEI & & CD PDDETFI & & KNIIIQDCMWSG \\
\hline \multicolumn{11}{|l|}{ Latimeria chalumnae } \\
\hline L-Myc & SSG DKL & $\mathrm{EW}$ & VS E FL & GA & $\mathrm{DEE}$ & QFKI & NP & & GEIWGNL & SSIIIHDCMWSG \\
\hline $\mathrm{N}-\mathrm{Myc}$ & WSG DPL & $\mathrm{DW}$ & As E LL & LL & $\mathrm{PE}$ & GDLW & SG & $C E$ GEEDQF & ELGSGSRLEQGNL & NAIILQDCMWSG \\
\hline C-Myc & STA DQL & sV & MD E IL & GV & SPEE & & & & KTKP & SSVTLHDDGFSG \\
\hline
\end{tabular}




\begin{abstract}
Human and viral Myc group
$\begin{array}{ll}\text { hsa L-Myc } & \text { inactive myc paralog } \\ \text { hsa N-Myc } & \text { active myc parapog }\end{array}$

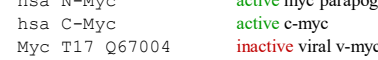

$\begin{array}{ll}\text { MYC_AVIM2 P10395* } & \begin{array}{l}\text { active viral v-myc } \\ \text { MYC deltion 106-143 }\end{array} \\ \text { active mutant c-myc }\end{array}$
\end{abstract}

C-Myc group

hsa-C
lch-C XP005992710

Ich-C XP005992710
cim-C XP007901659
rty-C XP020371961

bbe-c BAD93381

Cepletochodata Branchiostoma florida

$\begin{array}{ll}\text { aca-C XP003219450 } & \text { Reptilia Anolis carolinensis } \\ \text { pbi-C XP007438325 } & \text { Reptilia Python bivittatus }\end{array}$

L-Myc group

hsa-L
lch-L XP005993959
rty-L XP020379445

inactive myc paralog
lobe-finned bony fish Latimeria chalumnac

rty-L XP020379445
Xtr-L NP001011144
CPY-L M7B8E5

Reptilia Xenopus tropicalis

Reptilia Chelonia mydas

$\begin{array}{lll}\text { psi-L XP006139201 } & \text { Reptilia Pelodiscus sinensis } \\ \text { asi-L A0A1U7RG17 } & \text { Reptilia Alligator sinensis }\end{array}$

$\begin{array}{ll}\text { asi-L AOA1U7RG17 } & \text { Reptilia Alligator sinensis } \\ \text { gja-I XP015273252 } & \text { Reptilia Gekko japonicus }\end{array}$

$\begin{array}{ll}\text { afo-L XP009274523 } & \text { Aves Aptenodytes } \\ \text { gga- I F1NXY9 } & \text { Aves Gallus gallus }\end{array}$

ialia Sarcophilus harrisi

N-Myc group

hsa-N
lch-N XP006009573 lobe-finned bony fish Latimeria chalumnae

\begin{tabular}{ll} 
rty $-\mathrm{N}$ XP020371801 & jawed cartilaginous fish Rhincodon typus \\
\hline Reptilia Pelodiscus sinensic
\end{tabular}

$\begin{array}{ll}\text { Psi-N K7G066 } & \text { Reptilia Pelodiscus sinensis } \\ \text { gga-N E1C3E1 } & \text { Reptilia Gekko japonicus }\end{array}$

Distal Myc orthologs in early branched metazoans

hsa-C
mbr A9V5B4

mbr A9V5B4
aqu XP0033

tad B3S238
nve A7RIE4

hec AEG6693

hvu D2KBP8
lak A0A1S3JL92
cgi XP011441199

pfu AGS18763

mye XP021367
cte ELT88315
pdu AGS55451

Porifera Amphimedon queenslandica
Placozoa Tricholat

Clacozoa Irichoplax adhaerens

Protostomia brachiopoda Lingula unguis
Protostomia

Protostomin mollusca Crassostrea gigas

Protostomia mollusca Mizuhopecten y.
Prostostomia annelide Capitella telet

Protostomia annelida Platynereis dumeril
MYC box MBO MYC box MBO

MYC box MBI + T5

$\underline{9 a a}$

+ repeat

MYC box MBII

M DYD SYQHY FY DYD CGED FY $\quad$ F $\quad$ STAPSEDI WKKFELVPSPPTSPPW

PDEDDFYFGGPD

$\begin{array}{lll} & \end{array}$

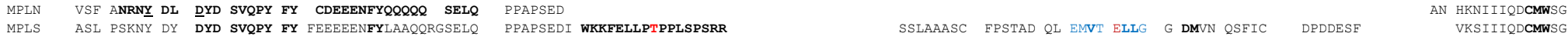

MPLN VSF TNRNY DL DYD SVQPY FY CD EEENFYQQQQQSELQ PPAPSEDI WKKFELLPTPPLSPSRR SGLCSPSYVAVTPESLRGDNDGGGGS FSTA D QL ENVT ELLG G DMVN QSFIC DPDDETE

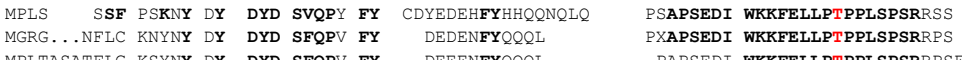
MPLITASATELG KSYNY DY DYD SFQPV FY DEEENFYQQQL PAPS PAPEDI WKKFELLPTPPLSPSRRPS \begin{tabular}{llll} 
MPGINAHAAVS VPSSK HY DFE SLQPY FY & EETDDPAREDDFYST \\
MPGINAHUVY & PSPSVPPSEDI WKKFELLPTPPRSPSHPAPK \\
\hline
\end{tabular} $\begin{array}{lllll}\text { MPLT } & \text { GPSF PSRTY DY } & \text { DYD SVQPY FY } & \text { FEDEEENFYLSAHNRGCELQ } & \text { PPAPSEDI WKKFELLPTPPLSPSRRGGC } \\ \text { MPLT } & \text { VPSY PSRAY DY } & \text { DYD SVQPY FY } & \text { YEDEEENFYLSAQHRGCELQ } & \text { PPAPSEDI WKKFELLPTPPISPSRRSGS }\end{array}$

$\begin{array}{lllll}M & \text { DYD SYQHY FY } & \text { DYD CGED } & \text { FY } & \text { RST } \\ M & \text { EYD TSQHY FY } & \text { DDD NEED } & \text { FY } & \text { RS } \\ M & \text { DS } & \text { DS }\end{array}$ MYEIATKANPAAHVTGGI LMQILTSEGGFATNNS.....

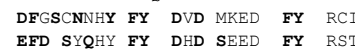
EFD SHQHY FY DHD SEED FY RS \begin{tabular}{llll} 
ELD SYQHY FY & DYD SEED & FY & RS \\
ELD PPHQPYFE & EAD POAED FH & & \\
\hline
\end{tabular} EFD SYQHY FY DHD AQED FH

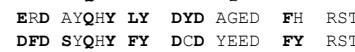

MPSC.. . TMPGM ICKNP DL EFD SLQPC FY PDEDDFYFGGPDS MPGV. MPG ISA SCKDY DI ET SYOPY FY PDDYGPEADF MPGM VSKNP DL EFD SLQPC FY PDEDDFYLCGPDS
MPGM ISKNP DL

MPLN VSF TNRNY DL DYD SVQPY FY CD EEENFYQQQQQSELQ $\begin{array}{llll}M & \text { SSF CAMSM SLD HLS PGMKN SF } & \text { E } \\ \text { MASL } & \text { VES GAE } & \text { LLP HLD EEKMO YM } & \text { AFTEAISFAEQFE }\end{array}$

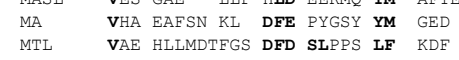

\begin{tabular}{llll} 
MTL & VAE HLLMDTFGS DFD SLPPS IF & RDF \\
MI & ITS ANRDLSVWS NID ESDNEETM & NLARPMMDD \\
\hline
\end{tabular} $\begin{array}{lll}\text { MT } & \text { GS NWC THD ILPTDEIL } & \text { LHKSILD } \\ \text { MPR } & \text { VQMKKMAHSLVKD DYE TFQPI YF } & \text { QDDNEDHLHA } \\ \text { M } & \end{array}$ MLIGRKNE KTA IM DYE MFQPC FY ENEPETI

MV VRT AKAHSHOM ENE MHRCQ T CDN

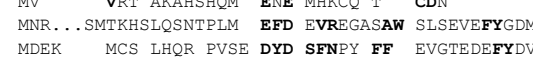

APSEDI WKKFELVPSPPTSPPW LIEEEDFYOTCEDF UKAVEVPTPPASPANITGD

APSEDI WKKFELVPG PLSPGGCP

PSEDI WKKFELVPTPPTSPLCSAAGK

APSEDI WKKFEIVPTPPTSPACGPADK

APSEDI WKKFEFVPTPPLSPLGE WKKFELVPSPPMSPPW

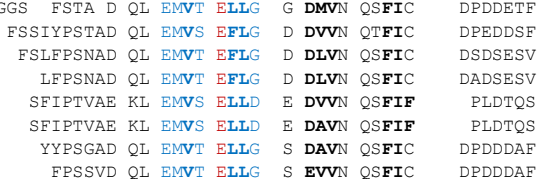

IKNI I IQDCMNSG IKNIIIQDCMNS
LKSI I IHDCMNSG LKSII IQDCMWS
LKSI I IQDCMWS LKSKLIIDDCMNS
LSSKLIDDCMNSG VRSIIIQDCMNSG
VKSIIIQDCMWSG $\begin{array}{rll}\text { YYPSGAD QL EMVT ELLG } & \text { S DAVN QSFTC } & \text { DPDDDA } \\ \text { FPSSVD QL EMVT ELIG } & \text { S EVWN QSFIC } & \text { DPDDDA }\end{array}$

\begin{tabular}{|c|c|c|c|c|c|}
\hline $\begin{array}{r}\text { GLGPGAGDPAPGIGP PE } \\
\text { NFYSSSGD KL } \\
\text { ICDSLSSLIPSKSD QI } \\
\text { GGG GT } \\
\text { ACCPGAEE RS } \\
\text { ACCPGAGE RS } \\
\text { ACCSGAAGE LG } \\
\text { A D } \\
\text { ACCSGAED RS } \\
\text { ACSAAEE RG } \\
\text { GSGSSPGACSSAANGPPE }\end{array}$ & \begin{tabular}{|l} 
Deletion \\
EW \\
EWVS EFLG \\
EIMS EFLLI \\
DWGA ELMD \\
DWLS \\
DRLS \\
DWL \\
GWLS \\
CPP \\
PWPGG
\end{tabular} & $\begin{array}{r}\text { PGGCTG } \\
\text { A } \\
\text { L } \\
\text { HCCLA } \\
\text { HCCLP } \\
\text { PSCCLA } \\
\text { YLI } \\
\text { RYCLA } \\
\text { RCCLP } \\
\text { CGV }\end{array}$ & $\begin{array}{l}\text { DEAESRGH } \\
\text { DEEQRKINP } \\
\text { DDEEISQS } \\
\text { GWESPMKLT } \\
\text { GEEPEYLIGT } \\
\text { GEEPEYLLGP } \\
\text { GEEP } \\
\text { EP } \\
\text { GEEPEYLIGT } \\
\text { DEPEYLIGT } \\
\text { DEAEGRGY }\end{array}$ & $\begin{array}{l}\text { SKGW } \\
\text { GEIW } \\
\text { LI } \\
\text { LL } \\
\text { GEIF } \\
\text { GAIL } \\
\text { GEIF } \\
\text { GGLL } \\
\text { GEIF } \\
\text { GQLE } \\
\text { SKAL }\end{array}$ & 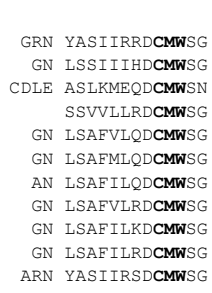 \\
\hline
\end{tabular}

TPPGEDI WKKEPITPTPPISPSR

GFAEHSSE PP SWVT EMLI ENELWGSPAEE DAFGL GGLGGLT PNPVILQDCMWSC

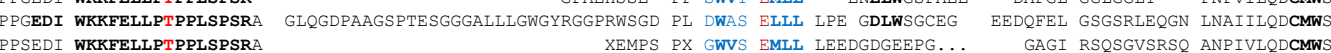

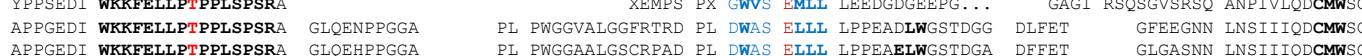

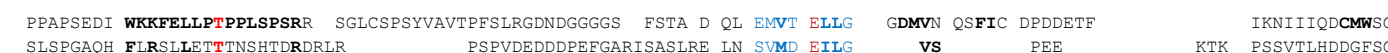

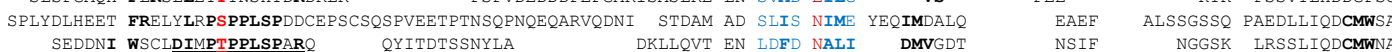

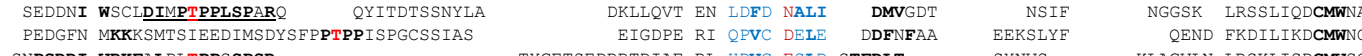
ISSPSDDV WKKF LTPPSSPOSIGESS

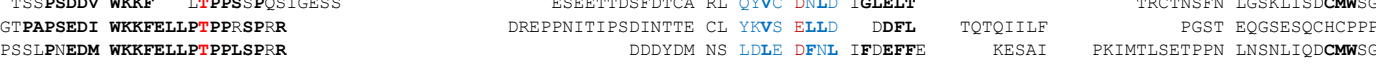
SPSSLPNEDM WKKFELLPTPPLSPRR GTTLCMNI WNKFDLGPPTPPGSPPH SSPNMDI WNKFEMGQPTPPASPER
PAPSEDI WKKFELLPTPPRSPKH

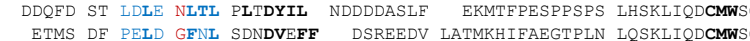
DSSTDGDDFS SO SMWD SITD SOTNE D DRO 
Graphical abstract

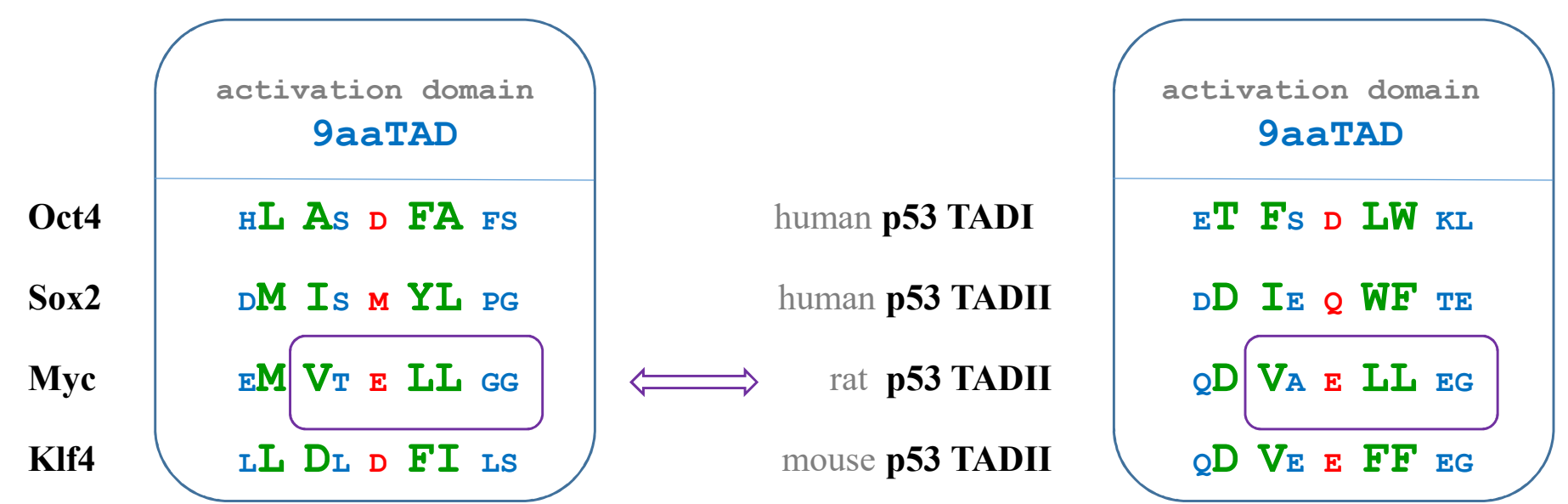

